\title{
Effectiveness and student perspective of a pilot effort in team based learning in pharmacology for medical undergraduate
}

\author{
Nayana K. Hashilkar ${ }^{1}$, Mark H. Gelula ${ }^{2}$, Netravathi B. Angadi ${ }^{1}$
}

${ }^{1}$ Department of Pharmacology, KLE University's J. N. Medical College, Belagavi, Karnataka, India

${ }^{2}$ Department of Medical

Education, University of Illinois, College of Medicine, Chicago, USA

Received: 01 May 2016

Accepted: 03 June 2016

*Correspondence to:

Dr. Nayana K. Hashilkar,

Email: drnayanakh@gmail.com

Copyright: (C) the author(s), publisher and licensee Medip Academy. This is an openaccess article distributed under the terms of the Creative Commons Attribution NonCommercial License, which permits unrestricted noncommercial use, distribution, and reproduction in any medium, provided the original work is properly cited.

\begin{abstract}
Background: Teaching in pharmacology is passive with less emphasis on clinical application. There is a need to incorporate newer instructional designs. Team based learning (TBL) is one such new strategy that encourages peer interaction and self-directed learning. The present study aimed to assess the effectiveness of team based learning to teach pharmacology to medical undergraduates as compared to tutorials. The secondary objective was to obtain the students attitudes regarding their experience.

Methods: The entire regular batch of MBBS in pharmacology was randomly divided into two groups. Four topics pertaining to cardiovascular system were selected that were notified to both the groups well in advance. One group received TBL as the instructional strategy while the other group had conventional tutorials dominated by a tutor. At the end of the cardiovascular module, a written test was conducted to assess the effectiveness of TBL and the mean scores of both the groups were analysed using unpaired t-test. The students were requested to provide feedback regarding their experience using a feedback form.

Results: The mean scores of the TBL group were significantly more as compared to the conventional tutorial group. The students in their feedback about the new teaching-learning strategy appreciated the group dynamics, team work and expressed their willingness for continuing TBL for rest of the topics in pharmacology.

Conclusions: Team-Based Learning is an effective teaching-learning method to teach pharmacology to medical undergraduates. It encourages pre-class preparation, student's participation in small teams and improves their basic knowledge as well as skills of critical thinking.
\end{abstract}

Keywords: Effectiveness, Student perspective, TBL, Pharmacology

\section{INTRODUCTION}

The science of pharmacology mainly deals with chemicals/drugs and their interactions with living systems. ${ }^{1}$ It is included as a para-clinical subject in the medical course. The main mode of teaching is through didactic lectures, small group tutorials and practicals. Lectures are often teacher centred that highlight on pharmacological aspects of drug classes with less emphasis on clinical application. The other mode of teaching that is followed is small group tutorials with an intention to increase student active participation and deal with clinical conditions so as to make pharmacology students competent enough to solve clinical problems. But, as we have seen at our institution and as supported by the literature, commonly tutorials are not taken seriously by the students and typically end being small group lectures by the tutors. ${ }^{2}$ Therefore, the students remain passive participants in the teaching- learning process, waiting for the tutor to "give them the answers". As such pharmacology teaching is very passive and restricting to just basics. This passive lecture-type approach does not provide enough knowledge and experience to students to deal with real world clinical problems.

Realising these loop holes in teaching learning process, the Medical Council of India (MCI), proposed that small group teaching which encourages peer interaction and self-directed learning as well as helping students develop qualities of communication, team work and professionalism should be incorporated to make learning 
effective. ${ }^{3}$ Therefore, to meet both the learning demands and MCI's requirements, new strategies need to be implemented into pharmacology teaching. Team based learning (TBL) is one such new strategy used in various curricula in India and world-wide. ${ }^{4-7}$

TBL was originally developed by Larry Michaelsen for business schools. ${ }^{8}$ It is a learner-centered, instructor led strategy with individual and group accountability process and involves small teams to work together to solve problems. ${ }^{8}$ The essential components involved in TBL include: ${ }^{2}$

- Advanced preparation: students come prepared for the session on the topic and material prepared and provided to them by the instructor.

- Team formation: the instructor divides the students into teams of 5-7 in each with varying diversities, background and abilities.

- Readiness assurance: the instructor administers a test consisting of multiple choice questions (MCQs) initially to each student (individual readiness assurance test-IRAT) and then the same set of questions to the teams (team readiness assurance test-TRAT).

- Group application exercise: the instructors provide challenging questions in the form of MCQs to the teams which is followed by extensive whole class discussion regarding their choice of answer.

- Peer evaluation: each student is evaluated by rest of the team members for their contribution to the team's productivity.

Considering these essential elements of TBL and the requirements of the medical profession for quality clinical decision making, the introduction of TBL into the pharmacology course at our institution was thought to be helpful to overcome the shortcomings of present teaching-learning methods. Therefore, the primary objective of the present pilot study was to assess the effectiveness of TBL to teach pharmacology with medical undergraduates as compared to conventional tutorials. A secondary objective was to obtain the students attitudes regarding their experience with the new method using a feedback form.

\section{METHODS}

The present study was planned for phase II MBBS students of pharmacology. The regular batch of 110 students was randomly divided into two groups. Group A received the conventional tutorial approach while group $B$ received TBL as the instructional method. Initially to begin we chose four topics pertaining to the cardiovascular system, viz. Renin angiotensin system, congestive cardiac failure, angina and hypertension. These topics had already been covered in lecture classes and were ready for tutorial sessions. All students were informed of the topics and associated reading materials fifteen days in advance. Group A then discussed these topics as were usually done with a major role played by the tutor. Group B's instructional strategy was TBL. Students in this group were divided into still smaller teams of 5-7 in each by the instructor. Team membership remained constant for the entire cardio vascular system module. Initially the students individually answered MCQs pertaining to basic knowledge (IRAT) and later in teams (TRAT). The answer sheets were collected from the students. Students then debated for their choice of the answer to the whole group with justification of the answer. Later the students were provided with MCQs that were related to clinical scenarios and were of higher level of cognition and requiring higher level clinical decision making. The students used their basic knowledge to solve these clinical problems and reported simultaneously their choice of answer followed by discussion of the right answer. At the end the instructor summarized the entire topic in brief and answered any outstanding questions and misunderstandings.

To assess the effectiveness of TBL over conventional tutorials a written test consisting of essay questions and short answer question was conducted for both the groups at the end of the module. The answer sheets of the students were evaluated by trained staff members. The data was expressed as Mean \pm SEM and the mean scores of both groups were compared using unpaired t-test. $\mathrm{p} \leq$ 0.05 was considered as significant. To determine student attitudes regarding TBL, a written feedback form with questions pertaining to inclusion of small group participation and perceived educational value of TBL was obtained at the end of the module. Students marked each statement ranging from strongly agree to strongly disagree. ${ }^{9}$ We also elicited their comments in writing regarding the new instructional strategy.

This study was approved by the institutional ethical committee and student informed consent was obtained before the beginning of the study.

\section{RESULTS}

The mean score of the end of the module test for the TBL group was significantly more $(\mathrm{p}=0.0182)$ as compared to conventional tutorial group (Table 1).

Table 1: Mean scores of the end of the module test.

\begin{tabular}{|lll|}
\hline & \multicolumn{1}{|c|}{$\begin{array}{l}\text { TBL group } \\
\text { N=49 }\end{array}$} & $\begin{array}{l}\text { Conventional } \\
\text { tutorial group N=46 }\end{array}$ \\
\hline $\begin{array}{l}\text { Module } \\
\begin{array}{l}\text { Assessment } \\
\text { Mean scores }\end{array}\end{array}$ & $15.33 \pm 0.4755^{*}$ & $13.70 \pm 0.4834$ \\
\hline $\mathrm{t}=2.404, \quad \mathrm{df}=90, \quad * \mathrm{p}=0.0182$. & \\
\hline
\end{tabular}

Regarding the feedback (Table 2) of the students about TBL, most of them agreed that inclusion of small group participation increased the extent and enhanced educational value of their involvement, improved their insight into the educational material and motivated them 
for preparation prior to attending the session. Students also expressed that group presentation at the end of session extended their basic knowledge and was a valuable learning experience. Students appreciated that the cases and questions effectively focussed small group participation.

Table 2: Students feedback regarding TBL (Data expressed as percentage).

\begin{tabular}{|c|c|c|c|c|c|}
\hline & SA & MA & MD & SD & DK \\
\hline $\begin{array}{l}\text { Inclusion of small group participation increased the extent } \\
\text { of my usual classroom involvement. }\end{array}$ & 85 & 15 & - & - & - \\
\hline $\begin{array}{l}\text { Inclusion of small group participation enhanced the } \\
\text { educational value of my usual classroom involvement. }\end{array}$ & 65 & 35 & - & - & - \\
\hline $\begin{array}{l}\text { Inclusion of small group participation improved insight } \\
\text { into educational material that was presented in classroom } \\
\text { sessions. }\end{array}$ & 70 & 30 & - & - & - \\
\hline $\begin{array}{l}\text { Inclusion of small group participation motivated my } \\
\text { preparation prior to attending class. }\end{array}$ & 78 & 15 & 3.5 & 3.5 & - \\
\hline $\begin{array}{l}\text { The educational value of small group participation was } \\
\text { worth the time that could have been otherwise available to } \\
\text { the lecture. }\end{array}$ & 76 & 22 & - & 2 & - \\
\hline $\begin{array}{l}\text { Participation in the group presentation at the end of the } \\
\text { unit extended my basic knowledge of the topic }\end{array}$ & 70 & 30 & - & - & - \\
\hline $\begin{array}{l}\text { Involvement in the group presentation process at the end } \\
\text { of the unit was a valuable learning experience in group } \\
\text { participation. }\end{array}$ & 72 & 28 & - & - & - \\
\hline $\begin{array}{l}\text { The cases and questions in the lecture effectively focused } \\
\text { small group participation. }\end{array}$ & 59 & 28 & 9 & 2 & 2 \\
\hline
\end{tabular}

SA-Strongly agree, MA-Moderately agree, MD-Moderately disagree, SD-Strongly disagree, DK-Don’t know.

\section{Student's positive comments regarding their experience with TBL were}

- Team activity helped a lot to learn

- Small group enabled to overcome hesitation to participate in class room activity

- Team system made one feel responsible to study the prescribed portion more effectively

- Very good method to improve basics, concepts stay for a longer time, less time to memorize which makes studying easier

- Very useful, as we used to read the entire book, yet never understand the key points and having MCQs based on the lines which otherwise we would overlook was the most beneficial part of TBL

- Very interactive and a great learning experience with active involvement in the discussion

- TBL should have been started earlier and should continue for other chapters also

- Developed interest in pharmacology.

\section{Students negative comments were}

- Time management should be maintained

- More clinical approach should be used

- Not possible to cover entire topic.

\section{DISCUSSION}

The primary objective of the present study was to assess the effectiveness of TBL to teach Pharmacology to medical undergraduates. It is clear from the results of this study that TBL is more effective method as compared to conventional tutorials and is supported statistically. This is in accordance with extant literature which revealed that TBL strengthens the attitudinal as well as cognitive foundation of the students. ${ }^{7,10}$ This type of teaching not only improves the basics of any topic but also provides scope to think at higher levels of cognition (critical thinking) as evidenced in the present study wherein assurance test questions were related to basics while the group assignment exercises included case scenarios. A similar concept was reported in a study which showed that active learning activities like this one were successful in teaching the student's knowledge needed to formulate therapeutic recommendations. ${ }^{11}$ Further as students come prepared to participate in class discussion increases as compared to traditional lecture. ${ }^{12}$ The end of the module test was conducted after the completion of all four sessions which took about a month. Since the student mean scores of the TBL group were higher than those of the tutorial group, it can be concluded that TBL helps in better retention and application of the material learned. Overall, TBL proved to be an effective method to teach pharmacology to medical undergraduates. 
Regarding the students experience about TBL, it is evident from this study, that students appreciated the new learning strategy. These findings suggest that TBL improves the quality of learning and helps in professional development. ${ }^{2}$ Small group teaching is not new in medical courses. These are often conducted as tutorials which often end up in being lectures by tutors with less active participation of the students. ${ }^{2}$ But, transforming groups into teams increases the willingness of the students to work at a higher level and solve problems collectively that are beyond individual capability. ${ }^{13}$ The results of our study, students views and literature suggest that TBL can be introduce to teach pharmacology to medical undergraduates

The characteristics of TBL make it a highly effective method of instruction provided the essential components are followed. This was the first time that TBL was introduced in our setting and therefore was planned only for one module. Also, though four topics were included in cardiovascular module, student's performance in each topic was not assessed separately. A further study is therefore recommended to assess student performance in individual sessions as well as entire module.

\section{CONCLUSION}

Team-based learning is an effective teaching-learning method to teach pharmacology to medical undergraduates. It encourages pre-class preparation, student's participation in small teams and improves their basic knowledge as well as skills of critical thinking.

\section{Funding: No funding sources}

Conflict of interest: None declared

Ethical approval: The study was approved by the Institutional Ethics Committee

\section{REFERENCES}

1. Kwan CY. Problem - based learning and teaching of medical pharmacology. Naunyn Schmiedeberg's Arch Pharmacol. 2002;366:10-7.

2. Parmelee DX, DeStephene D, Borges NJ. Medical students attitudes about team- based learning in a pre- clinical curriculum. Medical Education Online. 2009; $14: 1$.

3. Medical council of India-salient features of regulation on graduate medical education in Part III, Section 4 of the Gazette of India dated $17^{\text {th }}$ May 1997.

Available http:/mciinndia.org/know/rules/rules-mbbs.htm.

4. Thompson BM, Schneider VF, Haidet P, Levine RE, McMahon KK, Perkowski LC, et al. Team-based learning at ten medical schools: two years later. Medical Education. 2007;41:250-7.

5. Dinan FJ, Frydrychowski VA. A team learning method for organic chemistry. J chem. Education. 1995;72:429-31.

6. Mennenga HA, Smymer T. A model for easily incorporating team-based learning into nursing education. International Journal of Nursing Education Scholarship. 2010;7(4):1-13.

7. Shankar N, Roopa R. Evaluation of a modified team based learning method for teaching general embryology to $1^{\text {st }}$ year medical graduate students. Indian Journal of Medical Science. 2009;63:4-12.

8. Michaelsen LK. Three keys to using learning in groups effectively. Ames (IA) (professional and organizational development network essay series teaching excellence; Toward the best in the Academy. 1998;9:c1997.

9. Dunway GA. Adaption of team learning to an introductory graduate pharmacology course. Teaching and Learning in Medicine. 2005;17:36-42.

10. Haidet P, O’Malley KJ, Richards B. An initial experience with "team learning" in medical education. Academic Medicine. 2002;77:40-4.

11. Marshall L, Nykamp D. Active-learning assignments to integrate basic science and clinical course material. American Journal of Pharmaceutical Education. 2010;74:119.

12. Grady SE, Team-based learning in pharmacotherapeutics. American Journal of Pharmaceutical Education. 2011;75:136.

13. Michaelsen LK, Bauman KA, Fink LD. Team-based learning: a transformative use of small groups in college teaching. Sterling (VA): Stylus Publishing; 2004.

Cite this article as: Hashilkar NK, Gelula MH, Angadi NB. Effectiveness and student perspective of a pilot effort in team based learning in pharmacology for medical undergraduate. Int $\mathbf{J}$ Basic Clin Pharmacol 2016;5:1413-6. 